\title{
LINGUAGENS DE INDEXAÇÃO EM BIBLIOTECAS UNIVERSITÁRIAS: ESTUDO ANALÍTICO ,
}

\author{
INDEXING LANGUAGES IN UNIVERSITY LIBRARIES: \\ AN ANALYTICAL STUDY
}

\author{
Mariangela Spotti Lopes Fujita \\ Maria Carolina Andrade e Cruz ${ }^{b}$ \\ Bruna Otreira Muniz Patrícioc \\ Luciana Beatriz Piovezan Rio Branco ${ }^{d}$
}

\begin{abstract}
RESUMO
Introdução: A linguagem de indexação é uma parte fundamental da política de indexação, tendo em vista seu papel mediador na representação e recuperação da informação. Para conhecer a realidade em catálogos online de bibliotecas universitárias realizou-se estudo analítico sobre linguagem na política de indexação de bibliotecas universitárias. Objetivo: $O$ estudo analítico tem o objetivo de verificar o uso de linguagem de indexação pelos profissionais, qual(is) linguagem(ns) utilizam, a existência de manual de política de indexação e o uso de software de construção e manutenção disponível para o catalogador. Metodologia: Para isso, foi construído e aplicado questionário em amostra de bibliotecas universitárias da região sudeste do Brasil. Resultados: O questionário foi respondido por 60 bibliotecas com o seguinte perfil: $60 \%$ possui coleções especializadas de uma até quatro áreas de assunto, $73 \%$ das bibliotecas tem de 1 a 3 profissionais dedicados à indexação, $83 \%$ das bibliotecas integram uma rede ou sistema, 50\% participam de catálogos coletivos. Com relação ao uso, verificou-se que $49(89,1 \%)$ utilizam alguma linguagem de indexação, 25 (51\%) utilizam uma linguagem de indexação, sendo $20 \mathrm{com}$ linguagem própria sem uso de software específico para construção e manutenção, e 24 (49\%) mais de uma linguagem. Entre as bibliotecas que utilizam linguagem de indexação, 19 bibliotecas adotam procedimentos quando não são encontrados termos na linguagem, 17 bibliotecas atualizam a linguagem por meio de interoperabilidade semântica. A formalização da
\end{abstract}

\footnotetext{
${ }^{1}$ Fundamentado nos estudos teóricos e metodológicos sobre linguagem de indexação do projeto de pesquisa (FUJITA, 2015) desenvolvido com apoio da FAPESP e do CNPq; Adequação, ampliação e atualização do trabalho "Linguagens de indexação em bibliotecas universitárias brasileiras: diagnóstico preliminar das regiões sul e sudeste" apresentado como comunicação oral no X EDICIC 2016.

a Doutora em Ciências da Comunicação pela Universidade de São Paulo (USP). Professora da Universidade Estadual Paulista (Unesp). E-mail: mariangela.fujita@unesp.br

b Mestranda em Ciência da Informação na Universidade Estadual Paulista (Unesp). E-mail: maria.andradeecruz@gmail.com

c Bolsista de Treinamento Técnico-3 da Fundação de Amparo à Pesquisa do Estado de São Paulo (FAPESP). E-mail: bompatricio@gmail.com

d Doutoranda no Programa de Pós-Graduação em Ciência da Informação da Universidade Estadual Paulista (PPGCI-UNESP). E-mail: Ibpiovezan@gmail.com
} 
política de indexação em documento é realizada por $58,3 \%$ e apenas $22 \%$ não descrevem a linguagem de indexação. Conclusões: $O$ estudo analítico realizado com aplicação do questionário revela novos cenários no uso de linguagens de indexação em bibliotecas com avanços, problemas e lacunas que são verdadeiros desafios a serem enfrentados, em conjunto, pelos profissionais e pesquisadores.

Descritores: Organização do conhecimento. Indexação. Linguagens de indexação. Política de indexação. Bibliotecas universitárias.

\section{INTRODUÇÃO}

As bibliotecas universitárias estão inseridas em um ambiente de constante transformação e evolução através da produção científica dos discentes e docentes da universidade. A partir dessa perspectiva da realidade, a biblioteca universitária está voltada a fornecer meios de tratamento e disponibilização que auxiliem seus usuários no acesso à informação para propiciar geração e compartilhamento de conhecimento.

O papel da biblioteca universitária é fundamental para impulsionar as engrenagens de construção do conhecimento ao viabilizar o acesso à informação. Essa viabilização é possível com processos de tratamento temático e descritivo aplicados aos documentos de registros do conhecimento

No tratamento temático, o processo de indexação possibilita a identificação dos conceitos significativos do conteúdo documental por meio da linguagem de especialidade expressa pelo autor do documento. Porém, para cumprir o objetivo principal da indexação, o de intermediação entre usuário e documento no momento de busca e recuperação da informação, é desejável que haja uma uniformização da linguagem utilizada pelo autor do documento e a linguagem utilizada pelo usuário para a busca (BOCCATO; FUJITA, 2010).

Dito de outro modo, para que exista a uniformização dos discursos do autor e do usuário é necessário o uso de uma linguagem de indexação que cumprirá função comutadora e será a responsável por essa ação de intermediação. No âmbito dos Sistemas de Recuperação da Informação a escolha pelo uso de uma linguagem de indexação de um modo geral, assim como a escolha da linguagem específica a ser utilizada, está incluída nas decisões concernentes à política de indexação do sistema. 
É importante ressaltar que na política de indexação são abordados elementos e variáveis que direcionam o processo de indexação a determinados resultados de escolha do sistema de recuperação da informação. A escolha da linguagem de indexação é instrumento de representação da informação e importante elemento da política de indexação que direciona a especificidade e a exaustividade na representação durante a indexação e a busca (CARNEIRO, 1985; GUIMARÃES, 2004; GIL LEIVA, 2008).

Fujita e Santos (2016) realizaram estudo diagnóstico e analítico sobre política de indexação das bibliotecas universitárias do Sul e Sudeste brasileiro, cujos questionários aplicados foram respondidos por 39 bibliotecas. Conforme elementos e variáveis adotados, as autoras identificaram um padrão de classificação para a política de indexação em bibliotecas definido por estágios: estágio completo, parcialmente completo e incompleto com deficiências. A maioria das bibliotecas universitárias (27) dessa amostra tem política de indexação em estágio parcialmente completo em que um dos aspectos que caracterizam esse estágio é o fato de utilizarem linguagem natural e linguagem de indexação. Em sequência, no estágio incompleto com deficiências, verificouse que 8 bibliotecas utilizam apenas linguagem natural com uso de vocabulário próprio e 4 bibliotecas com política de indexação completa utilizam linguagem de indexação.

Considerando-se que a linguagem de indexação é uma parte fundamental da política de indexação, tendo em vista seu papel mediador na organização e recuperação da informação, tornou-se necessário o aprofundamento de investigação sobre linguagem na política de indexação de bibliotecas universitárias com base nas informações obtidas no artigo de Fujita e Santos (2016).

O aprofundamento tem o objetivo de verificar, mediante aplicação de questionário com amostra de bibliotecas universitárias, o uso de linguagem de indexação pelos profissionais, qual(is) linguagem(ns) utilizam, a existência de manual de política de indexação contendo informações sobre a linguagem de indexação utilizada e o uso de software de construção e manutenção de linguagem de indexação disponível para o catalogador. 


\section{LINGUAGEM DE INDEXAÇÃO NO CONTEXTO DA POLÍTICA DE INDEXAÇÃO É A ESQUERDA}

Obter controle de vocabulário é um dos objetivos principais das linguagens de indexação, também chamadas de linguagens artificiais, pois são construídas por especialistas que buscam a padronização dos termos compreendidos pelo vocabulário da linguagem de indexação. As linguagens de indexação possuem o propósito de contribuir para a organização e recuperação da informação, todavia, necessitam estar articuladas à política de indexação do sistema de recuperação da informação como uma das variáveis que influencia a recuperação da informação.

Para Carneiro (1985) políticas de indexação são orientações para a tomada de decisões no planejamento de sistemas de recuperação da informação, de forma a garantir que qualquer informação seja provida ao usuário no momento preciso, da maneira mais eficiente e econômica possível. Nesta visão, os objetivos almejados com o desenvolvimento de uma política de indexação são: definir as variáveis que afetam o desempenho do sistema de informação, estabelecer o critério e princípios que guiarão a tomada de decisões para tornar o sistema de informação mais eficiente, a racionalização dos processos e a consistência de suas operações (CARNEIRO, 1985).

Gil Leiva (2008) ainda estende o pensamento sobre a política de modo que esta, determine não apenas o modo como a indexação será realizada, mas também organize o esforço de consolidar, sistematizar e esclarecer por meio de manuais os processos realizados na indexação, garantindo a formalização (GIL LEIVA, 2008, p. 297).

Fujita (2012, p. 22) após análise das concepções existentes e considerando o contexto de gestão de sistemas de recuperação da informação, assim como os procedimentos e elementos de indexação, definiu a política de indexação como "[...] um conjunto de procedimentos, materiais, normas e técnicas orientadas por decisões que refletem a prática e princípios teóricos da cultura organizacional de um sistema de informação."

Carneiro (1985) elencou requisitos, elementos e variáveis que compõem 
a política de indexação. Segundo Fujita (2012), os requisitos referentes à organização, a clientela e os recursos financeiros, materiais e humanos estão em um plano administrativo, enquanto que os elementos e variáveis são relativos à organização e representação da informação. Os elementos da política de indexação são sete: cobertura de assuntos, seleção e aquisição de documentosfonte, processo de indexação, estratégia de busca, tempo de resposta do sistema, forma de saída e avaliação do sistema. As cinco variáveis exaustividade, especificidade, a escolha da linguagem, revocação e precisão, são definidas pelo sistema de recuperação da informação e vão influenciar diretamente a recuperação da informação.

Fujita (2012) completa que a determinação da política de indexação vai responder pela

[...] seleção de tipos de documentos a serem indexados, procedimentos de análise e representação de assuntos, aspectos qualitativos da indexação como precisão, especificidade, exaustividade e revocação, instrumentos de controle de vocabulário tais como linguagens documentárias ou opção por trabalhar com linguagem natural, além da avaliação da indexação pela consistência e pela recuperação (FUJITA, 2012, p. 22).

As variáveis são aspectos qualitativos da política de indexação que afetam a tanto a representação quanto a recuperação da informação e a escolha da linguagem é o principal instrumento de representação responsável pelo controle de especificidade, exaustividade e precisão. Embora, a decisão de se usar uma linguagem de indexação com controle de vocabulário seja mais acertada para o alcance do controle das variáveis da política de indexação, os sistemas de recuperação podem decidir pela opção de uso da linguagem natural tendo em vista os requisitos e elementos definidos pela política de indexação.

Entende-se que, em Organização do Conhecimento há uma distinção entre as linguagens, sendo estas a linguagem natural e a linguagem construída, também denominadas linguagens controladas, linguagens documentárias, assim como, linguagens de indexação. Barité (2015, p. 93) define linguagem de indexação como:

Linguagem natural ou vocabulário controlado utilizado para a representação temática dos assuntos contidos nos documentos e a recuperação dos documentos assim indexados. O idioma da 
indexação inclui termos e/ou símbolos e pode estabelecer os modos de ligação entre eles. É o elemento ideal de comunicação com o banco de dados em um sistema de armazenamento e recuperação de informações, quando se trata de pesquisas temáticas, e geralmente funciona em certos princípios ou regras que facilitam o diálogo (por exemplo, regras sintáticas ou de apresentação de termos de indexação).

A linguagem natural é a linguagem de uso corrente, que se encontra presente no discurso do autor (manifestada no documento), do indexador e do usuário. As linguagens construídas, que trataremos apenas de linguagens de indexação, são linguagens artificiais, construídas para servirem a um propósito específico, o de representação e recuperação da informação.

Desse modo, linguagem de indexação é uma denominação genérica para uma classe de instrumentos de organização do conhecimento, linguagens construídas com o propósito de aperfeiçoar o acesso à informação. De acordo com Lara (2004) essa denominação, além de designar uma classe de instrumentos, também "designa, de modo mais amplo e completo, a linguagem especialmente construída para organizar e facilitar o acesso e a transferência da informação" (LARA, 2004, p. 232).

De modo mais específico, Gil Urdiciain (2004) define linguagens de indexação como formas artificiais de linguagem que têm por princípio o controle terminológico e o propósito de aperfeiçoar o acesso à informação. Sua construção é realizada a partir de um conjunto de regras pré-estabelecidas em nível sintático, semântico e pragmático com fundamento em bases teóricas e metodológicas advindas da Linguística Geral, da semântica estrutural, da sintaxe, da Terminologia e da Linguística Textual (GIL URDICIAIN, 2004).

Utiliza-se a linguagem de indexação em dois momentos em um sistema de informação: na entrada - quando da análise do recurso que se pretende inserir no sistema, de modo que se realize a sua representação mediada pela linguagem de indexação; e, na saída do sistema - quando da busca por informação, de modo que o usuário expresse sua necessidade de informação utilizando-se, da mesma forma, de termos da linguagem de indexação (CINTRA et al., 2002).

Entre seus objetivos principais podemos destacar a promoção da representação consistente do conteúdo temático dos documentos, permitindo a 
compatibilização da linguagem utilizada no sistema e facilitar a recuperação da informação dotada de relevância e precisão (FUJITA, 2011). Sobre suas funções, podem ser destacadas como principais a função de conteúdo, que se refere à sua utilização no processo de indexação, na etapa de tradução dos conceitos; a função de uso, que se encontra na tradução das perguntas dos usuários para elaboração da estratégia de busca (BOCCATO, 2008); e a função de mediação, que a propósito de sua denominação, atua na relação autor, sistema e usuário permitindo a interação entre estas partes (MARTINS, 2014). Não obstante, em todas as utilizações tais linguagens destinam-se a orientar usuários do sistema de recuperação da informação a usar sempre os mesmos termos para representar os mesmos conceitos.

Deste modo, a linguagem atua na tradução da proposta de consulta do usuário, assim como, na tradução da linguagem natural do autor, materializada no documento, de modo a compatibilizar as ocorrências linguísticas. Para cumprir suas funções e atender a seus objetivos as linguagens de indexação integram três elementos, um léxico, composto por unidades linguísticas que serão usadas para indexar; uma sintaxe, regras para a utilização e combinação das unidades linguísticas, e uma rede de relações lógicas e semânticas, que atue na construção de um sistema inter-relacionando os conceitos (FUJITA, 2011; MARTINS, 2014).

De acordo com Gil Urdiciain (2004) existem diversos critérios de tipificação das linguagens de indexação, sendo os mais comuns: o de controle, podendo as linguagens serem livres ou controladas; estrutural, em que se dividem em linguagens combinatórias (como os sistemas de classificação) ou hierárquicas (tais como os tesauros); e, pelo momento da coordenação dos termos, que podem ser pré-coordenados ou pós-coordenados (GIL URDICIAIN, 2004).

Bastante popular também é a caracterização feita por Guimarães (1990) que aponta dois critérios para a classificação das linguagens: a apresentação dos conceitos, em que as linguagens podem ser alfabéticas ou hierárquicas; e a coordenação dos conceitos, que classifica as linguagens em pré-coordenadas ou pós-coordenadas. 
Podemos considerar especialmente a classificação entre sistemas précoordenados e pós-coordenados notadamente significativa para a observação e análise, posto que representam não apenas duas tipologias de linguagens, mas dois enfoques distintos dos processos de representação e recuperação da informação, cujos desenvolvimentos contemplam também as linguagens enquanto ferramentas que se aplicam nestes contextos.

Nos sistemas de indexação em que se opta pela pré-coordenação, os conceitos abrangidos pela linguagem são combinados pelo indexador no momento em que faz a representação do assunto do documento, estabelecendo a ordem dos conceitos a partir de sua percepção sobre qual será a estratégia de busca do usuário, mas principalmente, a partir de regras determinadas pelo sistema.

Os sistemas de indexação que elegem a pós-coordenação trabalham de forma a permitir que a combinação dos conceitos seja feita pelo usuário no momento da elaboração da estratégia de busca. Para isso o indexador realiza a representação do assunto do documento atribuindo separadamente cada conceito apropriado ao documento.

Para que as possibilidades apresentadas sejam possíveis, as linguagens pré-coordenadas e pós-coordenadas possuem estrutura sintática e semântica diferenciada, tendo sido elaboradas a partir de desenvolvimentos teóricos distintos. Entre as linguagens pré-coordenadas encontram se os sistemas de classificação e as listas de cabeçalhos de assuntos, entre as linguagens póscoordenadas apresentam-se o UNITERMO e os tesauros.

Martins (2014) deu destaque a um fenômeno que vem sendo observado nas listas de cabeçalhos de assunto e que a autora denominou como uma "progressiva tesaurização" tendo em vista o seu uso em sistemas digitais como os catálogos online e bases de dados. A autora afirma que embora estas listas tenham a capacidade de representar conceitos complexos, por meio da construção de cabeçalhos compostos por cadeias de assuntos, tais cabeçalhos foram planejados para buscas lineares, de modo que nos sistemas em que a busca se dá pela formulação e não pelo reconhecimento, se o usuário desconhece a forma como o cabeçalho foi elaborado não poderá recuperar a 
informação.

O exemplo mais destacado desse fenômeno pode ser observado na Library of Congress Subject Headings, linguagem construída como lista de cabeçalhos de assuntos pela Biblioteca do Congresso dos Estados Unidos e que se encontra atualmente dotada de características de linguagens póscoordenadas, tais como as referências TG (termo geral), TE (termo específico) e TR (termo relacionado).

Percebemos que esse fenômeno demonstra que as listas compostas por cabeçalhos de assunto apresentaram-se como solução eficaz para a representação de assuntos complexos e específicos em catálogos manuais, porém com as estruturas presentes nos sistemas de informação em âmbito digital, o uso de linguagens pós-coordenadas que conferem ao usuário maior autonomia na recuperação da informação tem se mostrado como mais adequado (MARTINS, 2014; CERVANTES, 2004).

Verifica-se na literatura de ciência da informação (CESARINO; PINTO, 1978; VAN SLYPE, 1991; SVENONIOUS, 2000; MOURA; SILVA; AMORIM, 2002; LANCASTER, 2004; GIL LEIVA, 2008) que o uso de instrumentos de controle de vocabulário é indicado para a representação precisa do sistema conceitual das diversas áreas de especialidade.

Vieira, Oliveira e Cunha (2017), analisaram o uso de políticas de indexação em bibliotecas universitárias goianas, identificando assim a ausência de formalização das políticas de indexação. As autoras apontam que $15 \%$ das bibliotecas utilizam política formalmente estabelecida, enquanto as demais declararam apenas fazer uso de regras e diretrizes que direcionam a indexação.

A política deve estar presente nas instituições não somente para estabelecimento de padrão na indexação ou norteamento de funcionários, mas também para que se tenha claro e previsto a atuação da biblioteca às necessidades dos usuários da instituição. Nesse sentido, a política deve considerar a missão, visão e objetivos da instituição. As autoras mencionam em suas considerações a necessidade do uso e formalização de políticas de indexação, destacando que as instituições têm consciência da importância das diretrizes apesar da ausência de documentação. 
Observa-se, portanto, a preocupação dos bibliotecários com a regularidade da indexação dos documentos, uma vez que, havendo ou não política documentada, prevalece o cuidado com a padronização e a observação da coerência no tratamento de assunto. Embora as diretrizes que norteiam o tratamento temático nas bibliotecas precisem ser mais bem reconhecidas em sua relevância, além de enxergados os benefícios de registrar e instituir oficialmente cada normativa nesse âmbito, evitando retrabalho e inconsistências no SRI da instituição (VIEIRA, OLIVEIRA, CUNHA, 2017, p. 46).

No conjunto analisado pelas autoras todas as instituições informaram utilizar diretrizes e regras para a execução das representações e em quais níveis os realizavam, e $45 \%$ das bibliotecas estudadas efetuavam compartilhamento dos registros com outras redes. Nesses casos, a inexistência de um documento que formalize os processos de tomada de decisão e justifique a forma com a qual a instituição executa seus registros pode dificultar o compartilhamento, pois a instituição que receber o compartilhamento não terá acesso aos princípios, procedimentos e padrões adotados e ponderar sobre utilização e adequação à instituição e ao usuário local.

Alertam assim que

[...] uma política de indexação - que exista de fato e não seja apenas fruto do consenso entre os profissionais em atividade é mais que oportuna, pois regulará e contribuirá com a descrição de assunto dos documentos, ao mesmo tempo em que trará maior assertividade para o indexador (VIEIRA, OLIVEIRA, CUNHA, 2017, p. 45).

Os registros e oficialização dos processos nas bibliotecas não têm o intuito exclusivo de padronização, rigor e observação na feitura dos procedimentos, mas contribui também para instituir e permitir o alinhamento que a biblioteca e o indexador estejam alinhados na mesma cultura e filosofia, trazendo benefícios múltiplos a instituição, como o "processo de gestão do conhecimento, uma vez que esse manual será elo fundamental para recém-contratados - bibliotecários ou auxiliares de bibliotecas - que não possuem a visão do SRI por falta de familiaridade com o ambiente" (VIEIRA, OLIVEIRA, CUNHA, 2017, p. 45).

O cenário investigado fez com que Vieira, Oliveira e Cunha (2017) considerassem que não há política de indexação formal nas bibliotecas universitárias goianas, acarretando em preocupação, pois o ambiente universitário, segundo as autoras, deve executar a maior quantidade possível de 
esforço ao tratamento da informação, iluminando a recuperação da informação, dando acesso aos usuários, possíveis geradores de conteúdo científico.

Apesar de não questionar em sua pesquisa a respeito de linguagens de indexação utilizadas pelas bibliotecas os dados apontam que $25 \%$ das bibliotecas estudadas não fazem uso de nenhum tipo de regra para a definição de preferência por termos gerais ou específicos, enquanto as demais informaram utilizar ambas as formas, o que, provavelmente, pode direcionar ao não uso de uma linguagem própria da rede ou da instituição. $O$ fato de as bibliotecas não utilizarem nenhuma regra revela a ausência de qualquer acordo ou estudo que as direcione, enquanto as demais podem utilizar, mas não há clareza de como se dá.

Desta forma, consideramos relevante observar como tem se dado a utilização de tais instrumentos nas bibliotecas universitárias brasileiras e a seção seguinte deste trabalho irá demonstrar os procedimentos adotados para realizarmos esta observação.

\section{METODOLOGIA}

O questionário foi adotado como principal instrumento de coleta de dados sobre o uso de linguagens de indexação em bibliotecas universitárias da região sudeste do Brasil. Para isso, a construção do questionário sobre linguagem de indexação teve uma trajetória, cujo ponto de partida foi o questionário sobre política de indexação em bibliotecas universitárias com etapas antecedentes.

Em 2010, foi iniciado projeto com aplicação de questionário que tinha como objetivo verificar "se os profissionais fazem indexação e se adotam uma política de indexação e manual de indexação com base nos estudos teóricos e metodológicos sobre indexação, política de indexação e experiências de elaboração de política de indexação e manuais de indexação" (FUJITA, 2010, p. 31). Através deste questionário pôde-se observar inadequações nas políticas de indexação que refletiam também no uso das linguagens de indexação (FUJITA; SANTOS, 2016).

Tendo em vista a necessidade de investigação especificamente a respeito das linguagens de indexação, em 2015 sob mesma coordenação, iniciou-se o 
projeto intitulado "Linguagem de indexação para bibliotecas na perspectiva da política de indexação" (FUJITA, 2015). Com isso, a fim de manter continuidade às pesquisas realizadas, agora com foco nas linguagens de indexação, foi elaborado um questionário específico.

$\mathrm{Na}$ elaboração do questionário foram seguidos os passos definidos por Barbosa (2008, p. 1): justificativa, definição dos objetivos, redação das questões e afirmações, revisão, definição do formato, pré-teste e revisão final. Os seguintes pontos foram delimitados por meio dessas diretrizes:

a) Justificativa: ampliar as investigações realizadas sobre linguagem de indexação dando continuidade às pesquisas anteriores.

b) Definição dos objetivos do questionário: Familiarização com o ambiente da biblioteca, em especial com o setor de tratamento temático da informação; Verificar se os profissionais utilizam linguagem de indexação, identificar qual(is) linguagem(ns) utilizam, verificar os procedimentos adotados quando a linguagem utilizada não contempla algum assunto, se essa(s) linguagem(ns) tem software de geração, manutenção e uso de linguagem de indexação; verificar se existe manual de indexação com aspectos de controle de vocabulário, projetos de aperfeiçoamento no âmbito do tratamento temático como elaboração de linguagem própria ou política de indexação caso não as tenham.

c) Redação das questões e afirmações: Inicialmente, para eventuais dúvidas em relação aos termos utilizados no questionário, foi elaborado um glossário priorizando uma explicação simplificada do significado dos seguintes termos:

Interoperabilidade semântica: recurso de construção de linguagens de indexação que utiliza a fusão com outras linguagens existentes.

Linguagem de indexação: Vocabulário controlado utilizado para a representação de conceitos de um documento (ANSI/NISO Z39.19:2005).

Linguagem natural: linguagem sem controle de vocabulário.

Linguagem própria: vocabulário controlado elaborado pela e para a instituição, por exemplo: a USP possui o Vocabulário Controlado USP.

Política/manual de indexação: Documento que apresenta as diretrizes de procedimentos para realizar a indexação.

O questionário está dividido em quatro categorias com 13 perguntas.

Cada questão foi elaborada tendo os objetivos como referência e com base na 
literatura sobre o tema. As questões se apresentam em diversos formatos: questões fechadas simples, fechadas com filtro, questões abertas e de múltipla escolha. As categorias foram denominadas de acordo com seus objetivos:

\section{Quadro 1 - Relação das categorias com os objetivos do questionário}

\begin{tabular}{|c|c|c|}
\hline Categorias & Perguntas do questionário & Objetivos \\
\hline $\begin{array}{l}2^{\mathrm{a}} \text { Indexação } \\
\text { na biblioteca }\end{array}$ & $\begin{array}{l}\text { 1. Número de profissionais dedicados a tarefas } \\
\text { de indexação } \\
\text { 2. Quais são as áreas de assunto que a coleção } \\
\text { cobre? } \\
\text { 3. A biblioteca está integrada a uma Rede ou } \\
\text { Sistema de Bibliotecas? } \\
\text { 3.1 Qual Rede ou Sistema? } \\
\text { 4. Faz parte de catálogo coletivo? } \\
\text { 4.1 Se faz parte de catálogo coletivo, indique } \\
\text { as instituições cooperantes com as quais } \\
\text { compartilha registros. }\end{array}$ & $\begin{array}{l}\text { Familiarização com o } \\
\text { ambiente da biblioteca, em } \\
\text { especial com o setor de } \\
\text { tratamento temático da } \\
\text { informação. }\end{array}$ \\
\hline $\begin{array}{l}3^{a} \text { Uso das } \\
\text { linguagens } \\
\text { de indexação }\end{array}$ & $\begin{array}{l}\text { 5 Utiliza linguagem de indexação para } \\
\text { indexação? } \\
\text { 6. É permitido o uso de mais de uma linguagem } \\
\text { de indexação? } \\
6.1 \text { Qual(is) linguagem? } \\
\text { 7. Anteriormente, a instituição adotou outra } \\
\text { linguagem de indexação? } \\
7.1 \text { Qual(is) outra linguagem de indexação? } \\
\text { 8. Utiliza palavras em linguagem natural (sem } \\
\text { controle de vocabulário) para a indexação? } \\
\text { 9. Quais são os procedimentos adotados } \\
\text { quando não são encontrados termos na } \\
\text { linguagem de indexação utilizada? } \\
\text { 10. A biblioteca realiza a manutenção da } \\
\text { linguagem de indexação contemplando a } \\
\text { interoperabilidade semântica? } \\
\text { 10.1 Quais as linguagens que são utilizadas } \\
\text { para interoperabilidade semântica? } \\
11 \text {. Existe algum projeto para elaboração e } \\
\text { implementação de uma linguagem própria, } \\
\text { caso ainda não a tenham? } \\
\text { 11.1 Qual o software que pretendem utilizar } \\
\text { para construção e manutenção da linguagem } \\
\text { própria? } \\
\text { 12. Qual o software para a manutenção da } \\
\text { linguagem que é utilizado? }\end{array}$ & $\begin{array}{l}\text { Verificar: } \\
\text { - se os profissionais } \\
\text { utilizam linguagem de } \\
\text { indexação; } \\
\text { - os procedimentos } \\
\text { adotados quando a } \\
\text { linguagem utilizada não } \\
\text { contempla algum assunto; } \\
\text { - se pretendem elaborar } \\
\text { uma linguagem de } \\
\text { indexação caso ainda não } \\
\text { a tenham; } \\
\text { - qual software de geração, } \\
\text { manutenção de linguagem } \\
\text { de indexação utilizam ou } \\
\text { pretendem utilizar. } \\
\text { - identificar qual(is) } \\
\text { linguagem(ns) utilizam. }\end{array}$ \\
\hline $\begin{array}{l}4^{\text {a }} \\
\text { Linguagem } \\
\text { de indexação } \\
\text { e política de } \\
\text { indexação }\end{array}$ & $\begin{array}{l}\text { 13. A biblioteca possui um documento } \\
\text { contendo a política de indexação utilizada na } \\
\text { biblioteca? (Política de indexação, manual de } \\
\text { serviços, roteiro de procedimentos, etc.). } \\
\text { 13.1 A linguagem de indexação utilizada está } \\
\text { definida neste documento? (Política de } \\
\text { indexação, manual de serviços, roteiro de } \\
\text { procedimentos, etc.) }\end{array}$ & $\begin{array}{l}\text { Verificar: } \\
-\quad \text { a presença de } \\
\text { documentos que } \\
\text { contemplam a indexação } \\
\text { na biblioteca, como política } \\
\text { de indexação, manual de } \\
\text { serviços, roteiro de } \\
\text { procedimentos, etc.; }\end{array}$ \\
\hline
\end{tabular}




\begin{tabular}{|l|l|l|}
\hline & $\begin{array}{l}\text { 13.2 Futuramente, pretende-se documentar a } \\
\text { política de indexação utilizada na biblioteca? }\end{array}$ & $\begin{array}{l}\text { - aspectos de controle de } \\
\text { vocabulário presentes } \\
\text { nesses documentos; }\end{array}$ \\
& $-\begin{array}{l}\text { projetos de } \\
\text { do tratamentomento no âmbito }\end{array}$ \\
& &
\end{tabular}

Fonte: Elaborado pelas autoras.

d) Revisão: adequação dos termos diante das discussões com o grupo de pesquisa e aprofundamento na literatura.

e) Pré-teste: as aplicações do pré-teste foram, inicialmente, presenciais em três bibliotecas universitárias de Marília - SP e posteriormente via e-mail para outras duas bibliotecas. Ao final das aplicações teste algumas questões do questionário foram reformuladas para melhor entendimento de respondentes futuros.

f) Definição do formato: para o pré-teste, optou-se por utilizar formato impresso, pois foi realizado presencialmente e, em seguida, em arquivo Word via e-mail para que as bibliotecas pudessem fazer seus comentários e opinar sobre o questionário. Diante dos testes realizados, buscou-se uma ferramenta que facilitasse o processo de resposta das bibliotecas, assim como a análise de dados. Com isso, utilizou-se a ferramenta disponível pelo Google: o Google Forms.

g) revisão final - a contribuição dos bibliotecários participantes foi essencial para o aprimoramento do questionário na fase de testes; a partir das aplicações testes foi possível identificar as perguntas que precisaram de modificação, por exemplo: adequação dos termos do questionário diante de comentários dos bibliotecários; adequação dos termos diante das discussões com o grupo de pesquisa e aprofundamento na literatura; eliminação de redundâncias e perguntas adicionais.

O envio dos questionários às bibliotecas da região sudeste deu-se por meio de uma lista organizada a partir das informações obtidas na "base de dados oficial e única de informações relativas às Instituições de Educação Superior e cursos de graduação do Sistema Federal de Ensino" do Ministério da Educação (MEC), o "Cadastro e-MEC de Instituições e Cursos de Educação Superior" dispõe de um recurso de busca onde é possível recuperar as instituições de ensino superior com cadastro e assim obter o seu contato. Para realizar contato 
com as bibliotecas de tais instituições foi necessário, portanto acessar os websites de cada uma das instituições recuperadas na busca do Cadastro e-mec da região Sudeste e localizar um meio de contato com o setor de biblioteca.

Conforme Marra (2012, p. 184), foi utilizado como ferramenta de coleta o site do e-MEC, com a intenção de obter o contato de instituições que estivesse em funcionamento regular e legal na região Sudeste. A elaboração da lista via e-MEC também se justificou pela ausência de compilações atualizadas de contatos das bibliotecas atuantes na região pesquisada. Tal cenário fez com que fosse providenciado uma busca pelos contatos das bibliotecas universitárias da região Sudeste via websites oficiais cadastrados no órgão governamental responsável.

Com um total de um mil duzentos e oitenta e sete (1287) Instituições de Ensino Superior da região Sudeste cadastradas no Cadastro e-mec, foi possível coletar 577 e-mails de contatos de bibliotecas, incluindo bibliotecas sedes das instituições cadastradas, admitindo-se, portanto, que uma única instituição cadastrada possuísse mais de uma biblioteca e coletando assim todos os contatos disponíveis.

\section{Quadro 2 - Instituições cadastradas no e-mec}

\begin{tabular}{|c|c|c|c|}
\hline Estado & Totais & Públicas & Privadas \\
\hline ES & 97 & 5 & 92 \\
\hline MG & 350 & 28 & 322 \\
\hline RJ & 151 & 29 & 122 \\
\hline SP & 689 & 98 & 591 \\
\hline
\end{tabular}

Fonte: Elaborado pelas autoras com base no e-mec.

Nem todas as instituições recuperadas possuíam cadastro atualizado, com informações de contato ou website. Outras ainda, apesar de conter em seu cadastro um website, não possuíam informações sobre sua identificação na instituição ou um e-mail de contato para o envio do questionário. Desta forma, foram descartadas as bibliotecas que não traziam nenhuma informação de contato, as que apenas informaram contato por telefone e/ou endereço e as que possibilitavam o contato por meio de formulário incorporado na página. 
Quadro 3 - Bibliotecas que disponibilizam e-mail de contato no site

\begin{tabular}{|l|l|}
\hline Estado & Envios \\
\hline ES & 51 \\
\hline MG & 283 \\
\hline RJ & 63 \\
\hline SP & 180 \\
\hline
\end{tabular}

Fonte: Elaborado pelas autoras.

Os questionários finalizados foram enviados para 778 bibliotecas e foram recebidas 60 respostas.

\section{Quadro 4 - Relação das bibliotecas participantes da pesquisa por estado}

\begin{tabular}{|c|c|}
\hline Estado & $\mathbf{N}^{\circ}$ de bibliotecas \\
\hline Espírito Santo & 3 \\
\hline Minas Gerais & 3 \\
\hline Rio de Janeiro & 16 \\
\hline São Paulo & 38 \\
\hline
\end{tabular}

Fonte: Elaborado pelas autoras.

Tendo como princípio a literatura analisada exposta no item anterior, pretende-se verificar como as bibliotecas universitárias utilizam linguagens de indexação. Portanto, através do corpus de análise desta pesquisa, pretende-se destacar correspondência com o verificado na literatura, sendo apontado pelos autores como requisitos e necessidades base para uma recuperação da informação adequada, com uso de linguagem de indexação e as demais ferramentas necessárias para um fazer profissional que de fato cumpra com o propósito de representar a informação e torná-la acessível aos usuários. Desta forma, ancorado na revisão de literatura feita no capítulo anterior serão abordados os resultados obtidos pela aplicação dos questionários nas bibliotecas universitárias da região sudeste do Brasil.

\section{APRESENTAÇÃO E DISCUSSÃO DOS RESULTADOS}

A apresentação e discussão dos resultados foram realizadas a partir das 
três categorias de análise das respostas do questionário: Indexação na biblioteca; Uso da linguagem de indexação; e, Linguagem de indexação e política de indexação.

\section{- Indexação na biblioteca}

A partir do objetivo de familiarização com o ambiente de tratamento temático da informação da biblioteca, as quatro questões pertinentes obtiveram dados sobre: número de profissionais dedicados à tarefa de indexação, áreas de assunto cobertas pela coleção da biblioteca, integração de bibliotecas em redes ou sistemas e participação em catálogo coletivo para compartilhamento de registros.

- Quantidade de Profissionais para execução das tarefas referentes a indexação

Verifica-se, conforme Figura 1, um padrão quanto ao número de profissionais dedicados a tarefas de indexação. Nas 60 bibliotecas analisadas, 43 delas dispõem de 1 a 3 profissionais dedicados à indexação, ou seja, este número compreende $73 \%$ do corpus analisados. Houve um único caso onde não foi informado a quantidade de profissionais que executam os procedimentos de indexação, pois todos os bibliotecários efetuam a tarefa na unidade.

Figura 1- Bibliotecários dedicados à indexação nas bibliotecas da Região Sudeste

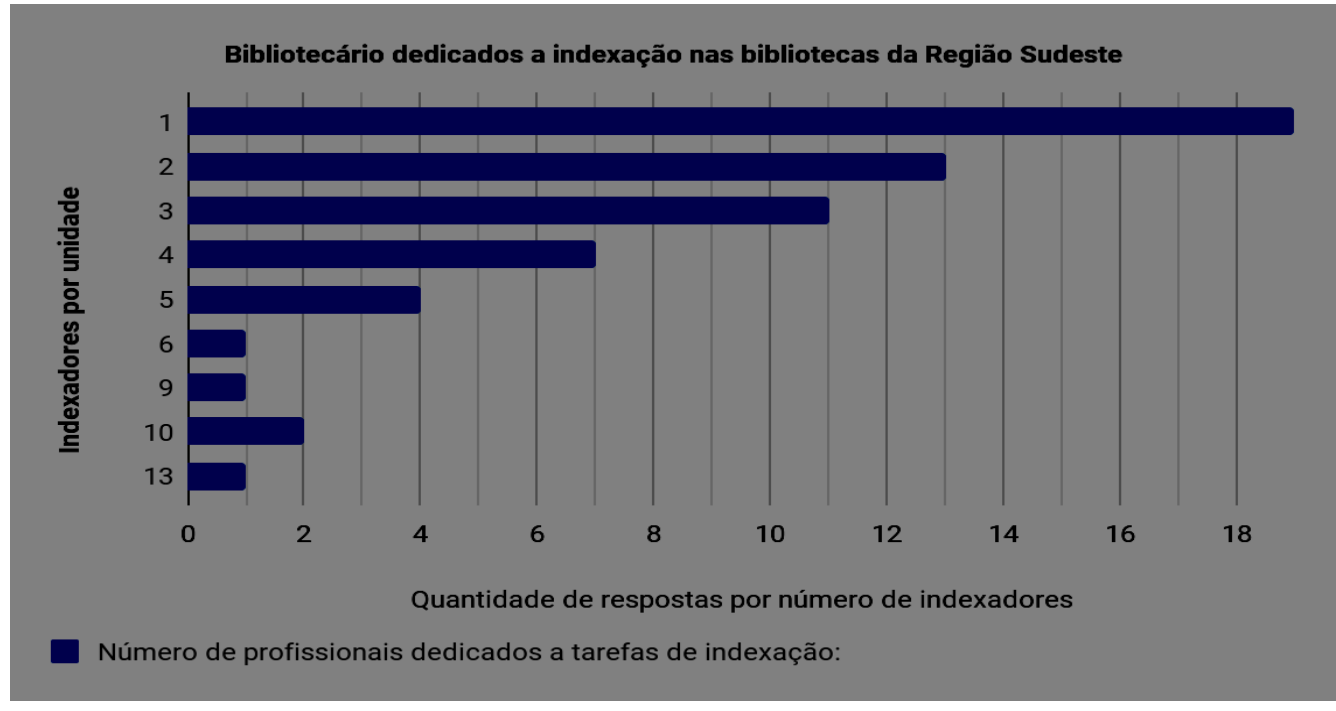

Fonte: Elaborado pelas autoras através do Google Forms. 
Por outro lado, observa-se que as bibliotecas com uma quantidade maior de profissionais dedicados a indexação, de 4 a 13 bibliotecários, são grandes universidades que fazem parte de uma rede de bibliotecas. Nesses casos, o trabalho é realizado visando o compartilhados os dados, pois fazem parte de um catálogo coletivo. É importante evidenciar nestes casos a necessidade de uma política de indexação, assim como a linguagem de indexação instituída e documentada buscando a uniformidade nas descrições realizadas (BOCCATO, 2012; FUJITA, 2012).

- Áreas de assunto cobertas pela coleção da biblioteca

Através do Google Forms foi elaborado um gráfico indicando genericamente as áreas de assunto cobertas pelas coleções das bibliotecas pesquisadas:

Figura 2 - Acervo das bibliotecas universitárias analisadas

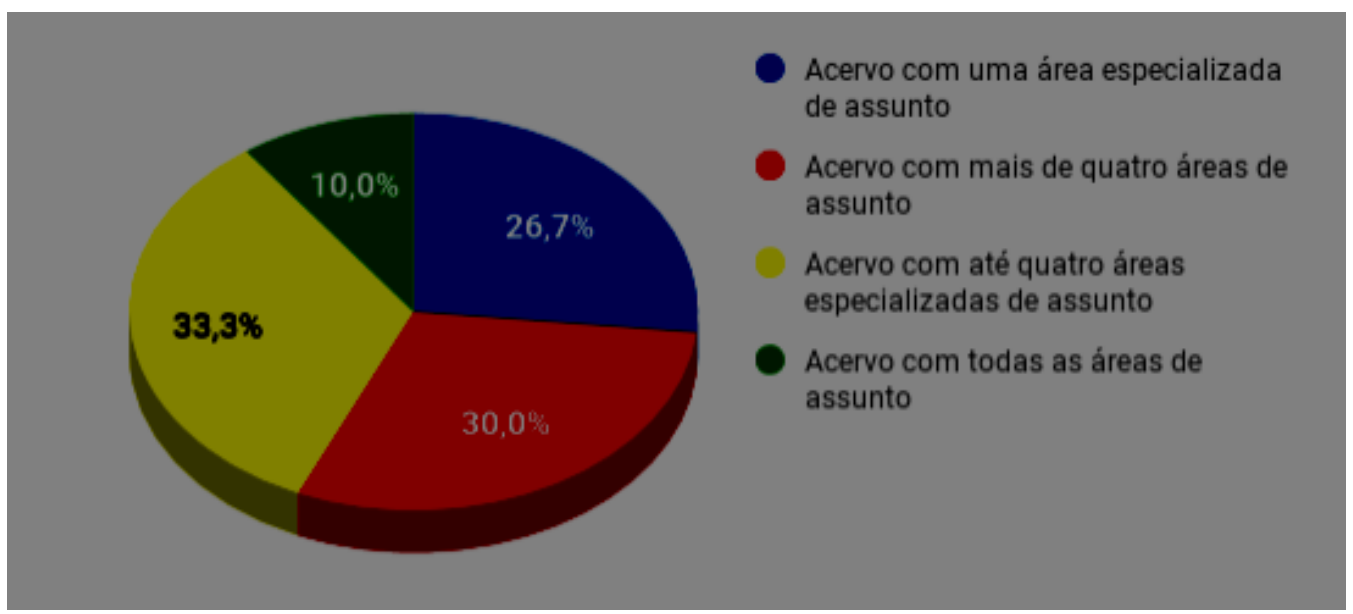

Fonte: Elaborado pelas autoras através do Google Forms.

Ao analisar as áreas cobertas pelas bibliotecas estudadas foi possível identificar que a grande maioria das bibliotecas se preocupam em atender as necessidades dos cursos oferecidos localmente, acarretando assim em dados como 18 de 59 bibliotecas informaram trabalhar com assuntos específicos, citando apenas uma grande área ou o foco exclusivo da biblioteca, por exemplo Teologia, Direito ou Ciências da Saúde. Algumas ainda informaram que seus acervos refletem as necessidades dos cursos locais. Em alguns desses casos os bibliotecários dispõem de conteúdos diversificados e específicos para representar, como por exemplo, em um mesmo acervo os temas de Ciências da Saúde, Educação, Metrologia e Processamento de Dados. Mas, em ambos os 
casos, as áreas acabam refletindo as necessidades que os cursos oferecidos pela instituição pedem. Enquanto isso, oito das 59 bibliotecas informaram tratar de temas gerais, ou possuir acervo que contemple todos os temas dentro das classes da Classificação Decimal de Dewey (CDD).

- Integração de bibliotecas em redes ou sistemas

Das instituições respondentes, 56 bibliotecas (83,6\%), informaram integrar uma rede e/ou um sistema de biblioteca em sua unidade. Apenas outras 11 não possuem esta característica.

Foram identificados 8 sistemas e 5 redes entre os respondentes:

- Rede de Bibliotecas Universidade Estadual Paulista (UNESP);

- Sistema Integrado de Bibliotecas Universidade de São Paulo (USP);

- Sistema de Bibliotecas e Informação da Universidade Federal do Rio de Janeiro (UFRJ);

- Sistema de Bibliotecas da Unicamp (SBU);

- Sistema de Bibliotecas dos Centros Federais de Educação Tecnológica Celso Suckow da Fonseca (CEFET);

- Redes de Bibliotecas Fiocruz

- Rede de bibliotecas da BIREME,

- Sistemas de Bibliotecas da Universidade Federal do ABC (SiBi/UFABC),

- Sistemas de Bibliotecas da Universidade São Francisco,

- Sistemas de Bibliotecas da Universidade Federal de Minas Gerais,

- Sistema Integrado de Bibliotecas da Universidade Federal de São Carlos (SiBi/ UFSCar).

- Rede de Bibliotecas da Unifesp (CRBU),

- Rede do Catálogo Coletivo Nacional (CCN),

Foram relatados também o Aleph, Pergamum, BNWeb, Sophia e o Personal Home Library $(P H L)$, porém esses são softwares de gestão de bibliotecas, não sendo uma rede de biblioteca tal qual o Sistema Integrado de Bibliotecas da Universidade Federal de São Carlos (SiBi/ UFSCar), por exemplo, que é uma rede com diferentes unidades.

- Participação em catálogo coletivo para compartilhamento de registros Quando questionadas a respeito da participação em catálogos coletivos, 
com o intuito de compartilhamento de registros, o grupo ficou dividido pela metade, já que 30 bibliotecas informaram compartilhar seus registros por meio catálogo coletivo, enquanto as outras 30 não compartilham. Foi solicitado informar quais as instituições cooperantes para o compartilhamento de catálogo. Houve uma diversidade de respostas, mas destacaram-se em ocorrência foram:

- Rede BIBLIODATA;

- Biblioteca Nacional;

- Catálogo Coletivo Nacional (CNN);

- Library of Congress;

- Rede Unesp;

- University of Oxford;

Foram citadas, também, outros catálogos coletivos para compartilhamento tais como: BookWhere, Instituto Federal de São Paulo (IFSP), Online Computer Library Center (OCLC), Personal Home Library (PHL), Pontifícia Universidade Católica (PUC), Rede de Bibliotecas da Área de Engenharia e Arquitetura (REBAE), Seriados em Ciências da Saúde (SeCS), Spines, Universidade Estadual de Campinas (UNICAMP), Universidade Federal de São Paulo (UNIFESP), Universidade Federal do Rio de Janeiro (UFRJ), Universidad Politécnica de Madrid, U.S. National Library of Medicine (NLM), University of Toronto, Universidad Nacional de Colombia (UNAL), University of Cambridge, Penn State University, , Yale Law School).

\section{- Uso da linguagem de indexação}

As análises dos resultados dessa categoria subdividem-se em nas seguintes subcategorias: quais linguagens de indexação são utilizadas, o uso de mais de uma linguagem de indexação, linguagens de indexação anteriormente utilizadas, uso de linguagem natural para indexação, os procedimentos adotados quando a linguagem utilizada não contempla algum assunto, manutenção da linguagem de indexação com interoperabilidade semântica, linguagens de indexação utilizadas para interoperabilidade semântica, projeto para elaboração e implementação de uma linguagem de indexação, software que pretendem utilizar para construção e manutenção de linguagem de indexação, software utilizado para manutenção da linguagem. 
- Linguagens de indexação utilizada pelas bibliotecas

As bibliotecas foram questionadas a respeito do uso de linguagens de indexação e se era possível o uso de mais de uma linguagem no processo de indexação. No entanto, foram identificadas algumas ocorrências de respostas que acusaram um possível erro de interpretação da questão. Alguns respondentes informaram não fazer uso de linguagem de indexação e logo em seguida informaram utilizar mais de uma linguagem, comprometendo assim os dados coletados. Tendo em vista o ocorrido, as cinco respostas que apresentaram estas características descritas acima foram descartadas do conjunto analise desta questão e da seguinte "Uso de mais de uma linguagem de indexação no tratamento da informação". Isto proporcionou um quadro de comparação em que, das bibliotecas estudadas, 49 (89,1\%) utilizam alguma linguagem de indexação e $6(10,9 \%)$ não fazem uso.

- Uso de mais de uma linguagem de indexação no tratamento da informação

Foi verificado que $25(51 \%)$ das 49 bibliotecas utilizam apenas uma linguagem de indexação para o tratamento dos documentos em seus respectivos sistemas de informação. No entanto, as outras 24 bibliotecas (49\%) possuem a prática de utilizar mais de uma linguagem. A pesquisa foi direcionada para bibliotecas universitárias e é sabido que as instituições, em sua maioria, oferecem uma variedade de cursos. Com isso, a cobertura de assuntos da biblioteca é abrangente. Ao definir uma linguagem é preciso entender qual seria a mais adequada para descrever os assuntos do acervo da biblioteca e de acordo com o nível de especificidade requerido.

Na questão aberta sobre as linguagens utilizadas uma biblioteca informou não utilizar linguagem de indexação por ainda não realizarem indexação na rede. Cabe ressaltar também algumas respostas incompatíveis com as perguntas realizadas: sete respondentes informaram apenas a tipologia da linguagem como, por exemplo, pré-coordenadas, lista de cabeçalho de assuntos, vocabulário controlado ou linguagem de indexação. Também houveram outras sete respostas que não podem ser consideradas como linguagens de indexação, como MARC 21, CDD, OCLC e Rede Pergamum. Com base nessas respostas, 
entende-se que falta compreensão sobre o processo de indexação e que a importação de registros bibliográficos de catálogos coletivos de compartilhamento é aceita sem compatibilização com a linguagem utilizada pela biblioteca universitária. Abaixo, a Figura 3 apresenta um gráfico referente as linguagens utilizadas pelas bibliotecas pesquisadas:

\section{Figura 3 - Linguagens de indexação utilizadas em bibliotecas universitárias do Sudeste do Brasil}

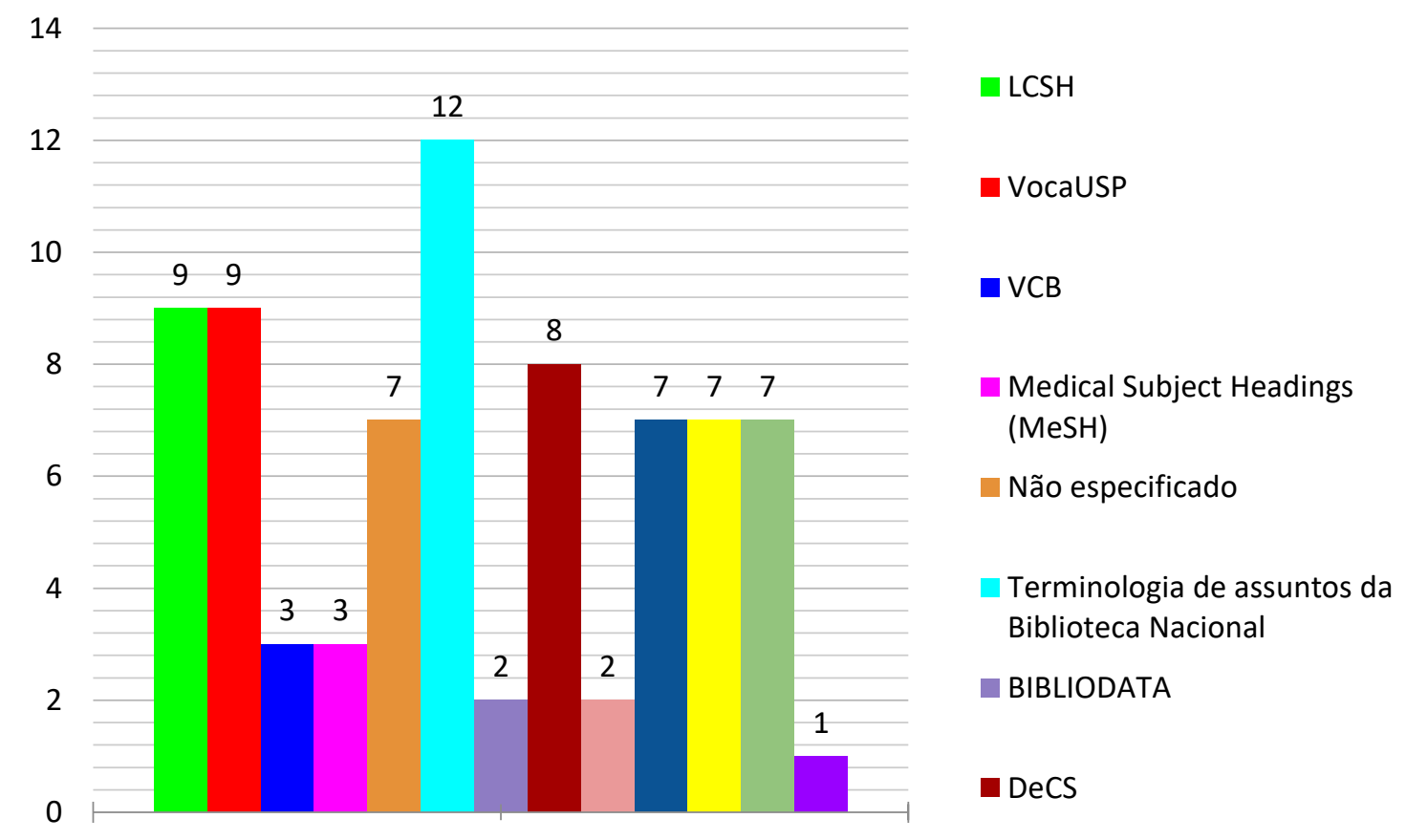

Fonte: Elaborado pelas autoras através do Google Forms.

*A biblioteca que apresenta linguagens específicas acerca de Aeronáutica utiliza: NASA Thesaurus (Engenharia Aeronáutica, Aeroespacial e áreas afins); ESJ Thesaurus (Engenharia Elétrica, Eletrônica e áreas afins); INIS Thesaurus (Física Nuclear, Engenharia Nuclear e áreas afins); Thesaurus of Mettalurgical Terms (Metalurgia e áreas afins); NCC -Thesaurus of Computing (Informática e Computação); Macrotesauro de transportes (Transportes); Tesauro Spines; Inspec Thesaurus; Macrothesaurus da OECD; Thesaurus Eric Descriptors; Thesaurus do Prodasen.

É interessante observar o exemplo da biblioteca que apresenta áreas de assunto em Aeronáutica, na qual utiliza várias linguagens de indexação para determinados assuntos específicos. Houve a preocupação de indicar para qual 
assunto geral é usada cada linguagem. Todavia, existem prós e contras no uso de várias linguagens de indexação para o tratamento de documentos em uma biblioteca/rede. Esta prática pode ser vantajosa para que se alcance um nível de especificidade maior na recuperação da informação, pois serão utilizados termos mais específicos para representar o documento. À medida que quanto mais especificidade houver na representação dos documentos, mais precisa será a taxa de recuperação (GIVEN; OLSON, 2003). Seguindo ainda o exemplo da biblioteca que apresenta áreas de assunto em Aeronáutica, percebe-se a preocupação em delimitar para qual assunto geral é usada cada linguagem. Isso pois, ao utilizar várias linguagens sem haver essa delimitação, ou seja, utilizar várias linguagens independente dos assuntos tratados na coleção da biblioteca, pode acarretar inconsistência de todo o trabalho de tratamento da informação e assim prejudicar a organização e recuperação da informação na biblioteca.

Ainda que haja esses pontos positivos em utilizar várias linguagens de indexação, é necessário observar de uma perspectiva mais ampla. A indexação faz parte de uma face da organização da informação e não é um apenas um procedimento técnico isolado na instituição. Sendo assim, o uso da linguagem de indexação deve assistir tanto o indexador como para o usuário no momento da busca, atuando como agente intermediário entre estes.

Rubi (2012) afirma que a disponibilização da linguagem auxilia o usuário e o bibliotecário nas consultas, nas opções que o sistema de recuperação da informação oferece e contribui para que decidam pelo termo que melhor represente suas necessidades de busca.

Sobre isso, Fujita (2016, p. 12) verificou que o uso de outras linguagens e até mesmo de linguagem natural contribuem para problemas de recuperação da informação por assuntos, pois não existe um padrão de linguagem para os catalogadores de assunto em sua tarefa "[...] e, o mais grave, nem para consulta do usuário durante a estratégia de busca por assuntos."

O uso de diversas linguagens de indexação causa várias questões que devem ser avaliadas com atenção considerando todos os pontos levantados. Contudo, acredita-se que o ideal seja o planejamento e investimento para a construção de uma linguagem própria capaz de atender a instituição com o 
respaldo da política de indexação e dos bibliotecários familiarizados com a realidade da biblioteca e usuários.

Como visto no gráfico acima, sete bibliotecas não realizam a indexação com ferramenta de controle de vocabulário tal qual uma linguagem de indexação. De acordo com a NBR 12676 (ABNT, 1992) o processo de indexação compreende essencialmente três etapas básicas: a análise do documento, identificação de conceitos e tradução dos conceitos nos termos de uma linguagem de indexação. Ressalta-se que a indexação é de fato exercida quanto todas suas etapas são aplicadas.

- Linguagens de indexação anteriormente utilizadas

Também foi questionado se anteriormente foi utilizada outra linguagem pela biblioteca. Verificou-se que 12 das 60 bibliotecas já utilizaram outras linguagens de indexação. Foram citadas: OECD Macrothesaurus Chapter Headings; PRODASEN; OMS; PubMed; LCSH; BIBLIODATA; Linguagem Natural; Linguagem não especificada; PesqBib; Lista de assuntos da CAPES. Três bibliotecas antes tinham uma lista de cabeçalho de assuntos elaborados por elas mesmas.

- Uso de linguagem natural para indexação

Quando questionadas sobre a utilização de palavras em linguagem natural (sem controle de vocabulário) para a indexação, 32 (53,3\%) informaram que não o fazem, enquanto as $28(46,7 \%)$ restantes responderam que sim. Esse quadro reflete a preocupação das bibliotecas em padronizar as entradas de assunto das bibliotecas de modo a terem um modelo pré-estabelecido para a representação.

Fazendo um paralelo com a questão anterior onde 49 bibliotecas analisadas utilizam linguagem de indexação no processo de indexação, pode-se observar que 14 bibliotecas além das linguagens utilizadas também utilizam termos em linguagem natural. Quando é realizada a junção de uma linguagem construída e controlada com uma linguagem natural faz com que a função primordial de controle de vocabulário seja perdida.

- Procedimentos adotados quando não são encontrados os termos na linguagem de indexação utilizada 
Com o intuito de verificar as medidas de tomada de decisões feitas pelas bibliotecas quanto ao momento de indexar novos termos, os quais ainda não se encontram previstos na linguagem de indexação utilizada, foi Ihes questionado o sobre o procedimento da seguinte forma: "Quais são os procedimentos adotados quando não são encontrados termos na linguagem de indexação utilizada?"

Para que fosse facilitada a análise dos dados todas as respostas foram divididas em quatro categorias: a) são adicionados novos termos (linguagem natural), b) Adequação a termos já existentes (atribuição de um termo mais geral, por exemplo), c) Decisão mediante estudo em grupo para adequação ou adição de termos, d) São adicionados novos termos mediante pesquisa.

a) A inserção de novos termos em linguagem natural é realizada por 17 bibliotecas quanto o termo não existe na linguagem de indexação utilizada. Dentre essas bibliotecas, a maioria dos respondentes informa que inserem o termo sem consultar ou realizar buscas, seja porque a indexação é realizada em linguagem natural, ou porque é utilizado um campo alternativo para a inserção do termo não localizado. Algumas das respostas enquadradas nesta categoria revelam que as bibliotecas efetuam pequenas pesquisas em dicionários e até com palavras-chave do próprio documento para encontrar o melhor termo a ser inserido no sistema.

b) Verificou-se que 14 bibliotecas adequam o termo não encontrado a outro já existente ou permitido, ação que pode trazer riscos à representação do significado. Os respondentes deste grupo, em sua maioria, informaram que a adequação tende a ser a um termo mais amplo, por exemplo "Vegetais" ao invés de "Alface".

c) Nesta categoria foram identificados, em 11 bibliotecas, casos de adequação e adição de termos realizados por grupo gestor da linguagem. É responsabilidade do grupo efetuar buscas e estudos a fim de que a decisão que melhor representar os objetivos da unidade/instituição sejam implementadas. Vale ressaltar o único caso em que é feita uma consulta a especialista da área para amparar a decisão de inclusão ou adequação do termo.

d) Dentre as 49 bibliotecas que responderam utilizar linguagem de 
indexação, 19 bibliotecas indicam que são adicionados novos termos mediante pesquisa. Nessa situação, as bibliotecas procuram realizar pesquisas em outros catálogos ou em materiais à disposição para apoiar a tomada de decisão e por fim fazem a inserção de um novo termo ao sistema/linguagem. Nesses casos, o indexador não compartilha sua decisão com um grupo gestor da linguagem e nem tem um manual de indexação; toma a decisão sobre o novo termo conforme orientações encontradas na pesquisa do termo.

- Manutenção da linguagem de indexação com interoperabilidade semântica

Cleveland e Cleveland (2013) apontam que o vocabulário tende a crescer diante dos novos documentos adicionados ao sistema. Dessa forma, entendese que as linguagens de indexação estão sempre em processo de construção. Para isso, é importante abordar a interoperabilidade entre as linguagens de indexação. A interoperabilidade semântica está relacionada a capacidade do sistema de construção de linguagens de indexação que utiliza a fusão com outras linguagens existentes. Através da pergunta direcionada à essa habilidade do sistema, 17 das 60 bibliotecas fazem a manutenção da linguagem por meio da interoperabilidade semântica. As linguagens de indexação utilizadas para esta tarefa foram relacionadas. Porém, como esta questão é aberta, algumas respostas não se enquadraram, pois não foram indicadas qual(is) linguagem(ns) de indexação são utilizadas para a interoperabilidade semântica ou não foram especificadas pelo respondente:

- Linguagens de indexação utilizadas para interoperabilidade semântica

Sete bibliotecas não especificaram a linguagem utilizada para interoperabilidade semântica. Quatro foram as bibliotecas que não indicaram linguagens de indexação usadas e sim padrões e códigos para catalogação descritiva como o MARC 21 e Código de Catalogação Anglo-Americano (AACR2r), foi mencionado também a Classificação Decimal de Dewey e linguagem natural.

As respostas que se enquadram como linguagem de indexação foram seis, no qual verificou-se o uso do: Vocabulário controlado da USP (VocaUSP), a Biblioteca Virtual de Saúde que utiliza os Descritores em Ciências da Saúde 
(DeCs), o Vocabulário Controlado Básico do Senado Federal (VCB); e três bibliotecas de uma mesma rede relacionaram: Medical Subject Headings (MeSH), Terminologia de assuntos da Biblioteca Nacional e Library of Congress Subject Headings (LCSH).

- Projeto para elaboração e implementação de uma linguagem própria

A figura abaixo nos mostra outro objetivo que o questionário tinha intenção de alcançar, verificar as bibliotecas que pretendem construir uma linguagem de indexação:

Figura 4- Bibliotecas que pretendem elaborar uma linguagem própria

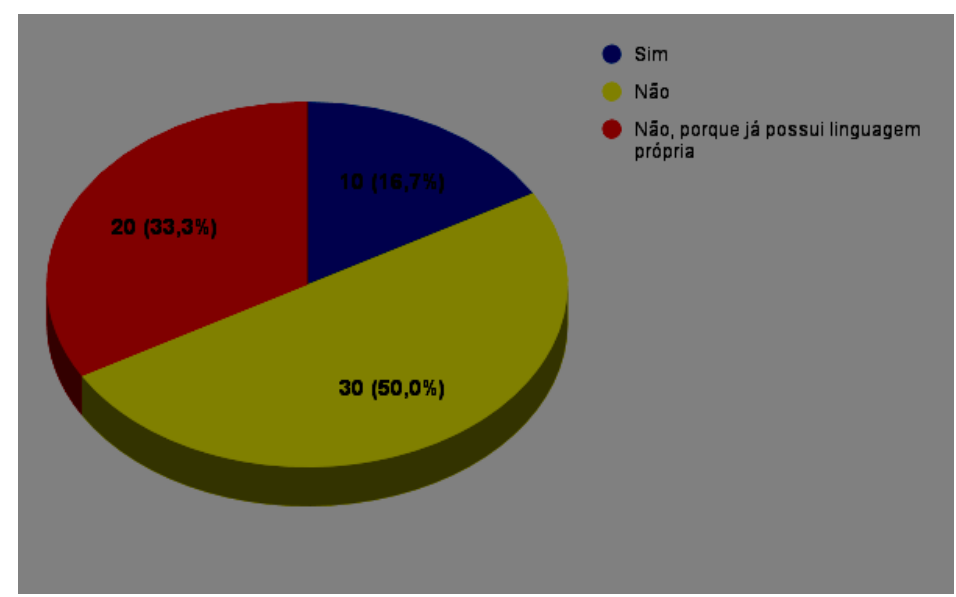

Fonte: Elaborado pelas autoras através do Google Forms.

Observa-se que metade das bibliotecas buscam melhorias em seus sistemas de informação, pois 20 delas já possuem linguagem de indexação elaborada pela biblioteca e 10 pretendem elaborar uma linguagem de indexação no futuro.

- Software que pretendem utilizar para construção e manutenção da linguagem própria

Dessas 10 bibliotecas que pretendem elaborar uma linguagem própria no futuro, a maioria ainda não conhecimento de software de gestão e manutenção de linguagens de indexação e relatam a necessidade de estudos para sua definição. Uma delas informou que inicialmente pretendem elaborar uma política de indexação antes de iniciar a construção da linguagem. Este fato é muito interessante, pois a política de indexação é fundamental para definições de aspectos sobre manutenção e construção relacionados a linguagem de indexação e pode influenciar positivamente na tarefa futuramente. Duas 
bibliotecas informaram softwares que não são específicos para gestão e manutenção da linguagem (ALEPH e Biblioteca Nacional) e uma única biblioteca citou o software TemaTres, específico para construção de tesauros.

- Software utilizado para a manutenção da linguagem

As bibliotecas universitárias, responsáveis pelo tratamento dos recursos informacionais, possuem coleções que contemplam conteúdos sobre novos conhecimentos e descobertas. Por isso, acompanham de perto as modificações de nomenclatura, surgimento de novos termos ou mesmo exclusão de um termo por não ser adequado ou obsolescente. Os softwares de construção e manutenção de linguagem disponibilizam serviços que auxiliam nas tarefas de alterações. A escolha do software deve ser realizada fundamentada em pesquisa sobre atendimento das necessidades da linguagem de indexação e do sistema de recuperação da informação.

Sobre as 20 bibliotecas que já possuem linguagem própria da biblioteca foi questionado qual o software utilizado para manutenção da linguagem, porém nenhum software de gestão de linguagem de indexação foi informado. As seguintes respostas demonstram o desconhecimento sobre softwares de gestão e manutenção de linguagens de indexação: o BIBLIODATA que corresponde a uma rede de catalogação cooperativa brasileira, o Structured Query Language (SQL) que é uma linguagem de programação, os softwares ALEPH, SIBIX, SOPHIA Biblioteca e TOTVS que são para gestão da biblioteca, e o DeCS e o $\mathrm{MeSH}$ que são linguagens de indexação.

Currás (2005) aponta que os softwares devem ser adequados para manuseio e manipulação, ou seja, precisam ser capazes de assegurar sua consulta e domínio para manutenção da linguagem de indexação. Verificou-se que as bibliotecas não indicaram um software adequado para a construção e manutenção de suas linguagens. Por essa razão, é importante investigar qual a linguagem mais interessante para a instituição e qual o software mais adequado para a construção, com a finalidade de estabelecer as relações sintáticas e semânticas, proporcionar a coordenação dos termos e a manutenção da linguagem.

\section{- Linguagem de indexação e política de indexação}


A partir das perguntas dessa categoria, foram analisados os resultados acerca dos objetivos de verificar: a presença de documentos que formalizam a política de indexação, aspectos de controle de vocabulário presentes no documento e projetos de aperfeiçoamento no âmbito do tratamento temático:

- Documentos que formalizam a política de indexação

Verificou-se que 35 (58,3\%) das 60 bibliotecas possuem um documento formalizado que contempla a política de indexação. Este resultado demonstra que as bibliotecas se preocupam com a oficialização dos procedimentos adotados no tratamento temático da informação. Ressalta-se que a política de indexação se torna um instrumento chave no sistema de informação, pois descreve todas as etapas, procedimentos e variáveis da indexação.

-Aspectos de controle de vocabulário presente nos documentos que formalizam a política de indexação

É bastante promissor considerar que, dessas 35 bibliotecas que possuem documento que formaliza a política de indexação, apenas oito $(22,8 \%)$ desses documentos não descrevem a linguagem de indexação utilizada pela instituição.

A linguagem de indexação tem uma função essencial no processo de indexação, na qual atribuem-se termos controlados para que haja padronização no catálogo das bibliotecas e maiores índices de recuperação da informação (GIL URDICIAIN, 2004; LARA, 2004; BARITÉ, 2015). Por essa razão, este trabalho buscou evidenciar o papel da linguagem de indexação e sua importância nas bibliotecas universitárias. Sendo assim, a política de indexação deve conter informações a respeito da linguagem utilizada (NARUKAWA; SALES, 2012), sobretudo quando a biblioteca/instituição possui linguagem de indexação própria. Pois, o trabalho que envolve na manutenção de um vocabulário construído pela instituição recebe frequentemente alterações de acordo com as novidades do campo científico.

- Projetos de aperfeiçoamento no âmbito do tratamento temático

Apesar de 25 bibliotecas (68\%) não possuírem a política de indexação documentada, 17 dessas bibliotecas informaram que futuramente pretendem elaborar e implantar proposta. O fato é que todos os sistemas que atuam com tratamento temático da informação, como as bibliotecas universitárias, possuem 
uma política de indexação informal sem registro. Essa política muitas vezes é passada do profissional mais experiente para o iniciante em treinamentos informais no cotidiano. Sob a percepção dessa prática comum nas bibliotecas, ressalta-se a contribuição da política de indexação estabelecida em um documento. Todos os procedimentos que envolvem a indexação estarão relacionados e, principalmente, institucionalizados para que haja convergência nas decisões realizadas pelos bibliotecários (NUNES, 2004; GIL LEIVA, 2008; FUJITA, 2016).

\section{CONSIDERAÇÕES FINAIS}

Estudos sobre uso de linguagens de indexação em bibliotecas não são usuais na literatura porque bibliotecas estão mais associadas ao tratamento descritivo pela catalogação e ao tratamento temático da catalogação de assuntos com uso de listas de cabeçalhos de assunto. Mas, o estudo analítico realizado com aplicação do questionário revela novos cenários no uso de linguagens de indexação em bibliotecas com avanços, problemas e lacunas que são verdadeiros desafios a serem enfrentados, em conjunto, pelos profissionais e pesquisadores na área de Organização e Representação do Conhecimento.

O principal desafio a ser enfrentado diz respeito ao problema de falta de compreensão pelos profissionais da função mediadora da linguagem de indexação na representação e recuperação da informação que garante ao documento ser representado na indexação e recuperado na estratégia de busca pelos mesmos termos de uma mesma linguagem de indexação.

Os resultados relativos à essa incompreensão estão demonstrados pelo uso de várias linguagens de indexação por 24 bibliotecas na tentativa de busca pela especificidade na representação, porém, sem 0 alcance da representatividade na estratégia de busca pelo usuário na recuperação. Verificamos, adicionalmente, que nenhuma dessas bibliotecas disponibiliza a linguagem de indexação na interface de busca para consulta dos usuários. Provavelmente, seria muito complexo ao usuário consultar mais de uma linguagem de indexação para elaborar sua estratégia de busca.

Além disso, o uso de várias linguagens de indexação para cada assunto 
específico deve, com certeza, aumentar a complexidade da representação na indexação para o profissional. Caso essa representação com várias linguagens não seja devidamente orientada por meio de diretrizes precisas e correspondentes, os profissionais não terão critérios definidos para o uso linguagens de indexação. Os resultados apontam apenas uma biblioteca de Aeronáutica que indica o uso de linguagens de indexação diferentes para cada assunto específico.

Por outro lado, o avanço considerável foi observado em 20 bibliotecas, um terço do total de 60 da amostra, que desenvolvem linguagem própria e 10 que pretendem construir. Esse dado é muito relevante e demonstra uma tendência da gestão do tratamento temático com política de indexação que define ações equilibradas entre a representação e a recuperação da informação.

Todavia, a principal lacuna a ser evidenciada é, certamente, relacionada à esse avanço porque diz respeito ao desconhecimento de softwares de gestão e manutenção de linguagens de indexação e a possibilidade de construção compartilhada de linguagens de indexação pela interoperabilidade. O único software citado por uma biblioteca foi o TemaTres que tem vários dispositivos que facilitam seu uso articulado aos softwares de gestão de bibliotecas.

$O$ fato de bibliotecas terem citado softwares de gestão de bibliotecas, como ALEPH, SIBIX, SOPHIA e TOTVS, é compreensível porque deve existir um módulo para a gestão de linguagens de indexação. Apesar desses softwares de gestão serem completos, é preciso verificar se contém módulos de gestão e manutenção de linguagens de indexação em conformidade com a normalização vigente. Tal proposta se configura em uma importante providência para muitas bibliotecas que relataram a necessidade de construção de linguagem própria tendo em vista os problemas de uso de várias linguagens para os profissionais e a necessidade de disponibilização de uma linguagem para consulta do usuário na estratégia de busca.

Catálogos online de bibliotecas são, atualmente, bases de dados importantes articuladas com bibliotecas digitais e repositórios que compartilham e realizam interoperabilidade tecnológica em nível avançado. $O$ estudo analítico tem o mérito de evidenciar a realidade das bibliotecas no que tange ao 
tratamento temático, principalmente, mudanças importantes sobre uso de linguagens que solicitam a necessidade de trabalho conjunto entre profissionais e a comunidade científica.

\section{REFERÊNCIAS}

ASSOCIAÇÃO BRASILEIRA DE NORMAS TÉCNICAS (ABNT). NBR 12676: métodos para análise de documentos - Determinação de seus assuntos $\mathrm{e}$ seleção de termos de indexação - Procedimento. Rio de Janeiro, 1992.

AMERICAN NATIONAL STANDARD/NATIONAL INFORMATION STANDARDS ORGANIZATION. ANSI/NISO Z39.19 Guidelines for the Construction, Format, and Management of Monolingual Controlled Vocabularies. Bethesda: NISO Press, 2005. $179 \mathrm{p}$.

BARBOSA, E. F. Metodologia da pesquisa: instrumentos de coleta de dados em pesquisas educacionais. 2008. Disponível em:

http://www.inf.ufsc.br/ vera.carmo/Ensino_2013_2/Instrumento_Coleta_Dados_ Pesquisas_Educacionais.pdf. Acesso em: 23 set. 2017.

BARITÉ, M. Diccionario de organización del conocimiento: clasificación, indización, terminología. 6. ed. Montevideo: CSIC, 2015. Disponível em: https://www.colibri.udelar.edu.uy/handle/123456789/9028. Acesso em: 18 out. 2017.

BOCCATO, V. R. C. A linguagem documentária como instrumento de organização e recuperação da informação. In: HOFFMAN, W. M.; FURNIVAL, A. C. (Org.). Olhar: ciência, tecnologia e sociedade. São Paulo: Pedro e João, CECH-UFSCar, 2008. p. 269-278.

BOCCATO, V. R. C. O contexto sociocognitivo do indexador no processo de representação temática da informação. Encontros Bibli, v. 17, p. 67-86, 2012. Disponível em: https://periodicos.ufsc.br/index.php/eb/article/view/15182924.2012v17nesp1p67. Acesso em: 26 ago. 2017.

BOCCATO, V. R. C.; FUJITA, M. S. L. O uso de linguagem documentária em catálogos coletivos de bibliotecas universitárias: um estudo de avaliação sociocognitiva com protocolo verbal. Perspectivas em Ciência da Informação, p. 23-51, 2010. Disponível em: http://www.scielo.br/pdf/pci/v15n3/03.pdf. Acesso em: 26 ago. 2017.

CARNEIRO, M. V. Diretrizes para uma política de indexação. Revista da Escola de Biblioteconomia da UFMG, Belo Horizonte, v. 14, n. 2, p. 221-241, set. 1985. Disponível em: http://www.brapci.inf.br/index.php/article/view/0000002649/422f489505a67213c ba8556004958487/. Acesso em: 25 ago. 2017. 
CERVANTES, B. M. N. Contribuição para a terminologia do processo de inteligência competitiva: estudo teórico e metodológico. 2004. $183 \mathrm{f}$. Dissertação (Mestrado em Ciência da Informação) - Universidade Estadual Paulista, Faculdade de Filosofia e Ciências, Marília, 2004. Disponível em: https://repositorio.unesp.br/handle/11449/93723. Acesso em: 25 ago. 2017.

CESARINO, M. A. N.; PINTO, M. C. M. F. Cabeçalho de assunto como linguagem de indexação. Revista da Escola de Biblioteconomia da UFMG, Belo Horizonte, v. 7, n. 2, p. 268-288, 1978. Disponível em: http://www.brapci.inf.br/index.php/article/view/0000001991/41d251f63e7744e1f ee36986a3780073/. Acesso em: 23 ago. 2017.

CINTRA, A. M. M.; TÁLAMO, M. de F. G. M.; LARA, M. L. G. de; KOBASHI, N. Y. Para entender as linguagens documentárias. Rio de Janeiro: Polis, 2002.

CLEVELAND, D. B.; CLEVELAND, A. D. Introduction to indexing and abstracting. 4. ed. Santa Barbara, California: Libraries unlimited, 2013.

CURRAS, E. Ontologías, taxonomías y tesauros: Manual de construcción y uso. Gijón: Trea, 2005.

FUJITA, M. S. L. Linguagem de indexação para bibliotecas na perspectiva da política de indexação. Marília: UNESP; FAPESP, 2015. (Projeto de Pesquisa).

FUJITA, M. S. L. Política de indexação para bibliotecas. Marília: UNESP; CNPq, 2010. (Projeto de Pesquisa).

FUJITA, M. S. L. A política de indexação para representação e recuperação da informação. In: GIL LEIVA, I.; FUJITA, M.S.L. Política de indexação. São Paulo: Cultura Acadêmica; Marília: Oficina Universitária, 2012. p. 17-28.

FUJITA, M. S. L. Política de Indexação para Bibliotecas: Funções e Finalidades. In: FUJITA, M. S. L. (Org.) Política de indexação para bibliotecas: elaboração, avaliação e implantação. Marília: Oficina Universitária; São Paulo: Cultura Acadêmica, 2016. Disponível em: https://www.marilia.unesp.br/Home/Publicacoes/politicas-de-indexacao-parabibliotecas_ebook.pdf. Acesso em: 23 set. 2017.

FUJITA, M. S. L.; SANTOS, L. B. P. Política de indexação em bibliotecas universitárias: estudo diagnóstico e analítico com pesquisa participante. TransInformação, Campinas, v. 28, n. 1, p. 59-76, jan./abr. 2016. Disponível em: http://periodicos.puccampinas.edu.br/seer/index.php/transinfo/article/view/2732/2228. Acesso em: 12 set. 2017.

FUJITA, M. S. L. Modelos de Categorização para a Construção de Tesauros: metodologia de ensino. In: BOCCATO, V. R. C.; GRACIOSO, L. de S. Estudos de linguagem em Ciência da Informação. Campinas: Alínea, 2011. 
GIL LEIVA, I. Manual de indización. Gijón: Trea, 2008.

GIL URDICIAIN, B. Manual de lenguajes documentales. 2. ed. rev. e aum. Gijón: Trea, 2004.

GIVEN, L. M.; OLSON, H. A. Knowledge organization in research: a conceptual model for organizing data. Library \& information Science Research, v. 25, n. 2, p. 157-176, 2003. Disponível em:

http://ac.elscdn.com/S0740818803000057/1-s2.0-S0740818803000057main.pdf?_tid=9f288cc8-5d98-11e6-95d5-

00000aacb̄35f\&acdnat=1470682256_d2529d056accb393654f95f369d7f32c.

Acesso em: 08 ago. 2016.

GUIMARÃES, J. A. C. A recuperação temática da informação. Revista Brasileira de Biblioteconomia e Ciência da Informação, São Paulo, v. 16, n. 3/4, p. 112-130, 1990. Disponível em:

http://www.brapci.inf.br/index.php/article/view/0000002799/66844f64b006528b6 536e3e344a92f4d/. Acesso em: 20 set. 2017.

GUIMARÃES, J. A. C. As políticas de indexação como elemento para a gestão do conhecimento nas organizações. In: VIDOTTI, S. A. G. (Coord.) Tecnologia e conteúdos informacionais: abordagens teóricas e práticas. São Paulo: Polis, 2004. p. 43-52.

LANCASTER, F. W. Indexação e resumos: teoria e prática. 2. ed. Brasília: Briquet de Lemos, 2004.

LARA, M. L. G. de. Linguagem documentária e terminologia.

Transinformação, v. 16, n. 3, p. 231-240, 2004. Disponível em:

http://periodicos.puccampinas.edu.br/seer/index.php/transinfo/article/view/710/6 90. Acesso em: 16 set. 2017.

MARRA, P. S. C. O papel das bibliotecas universitárias na comunicação científica: um estudo sobre os repositórios institucionais. Encontros Bibli:

Revista Eletrônica de Biblioteconomia e Ciência da Informação, v. 17, n. esp. 2, p. 174-194, 2012. Disponível em:

https://periodicos.ufsc.br/index.php/eb/article/view/1518-

2924.2012v17nesp2p174. Acesso em: 25 set. 2017.

MARTINS, M. C. B. Indexação e controlo da terminologia em bibliotecas do ensino superior politécnico em Portugal: o sistema no instituto politécnico de Portalegre. 2014. 372 p. Tese (Doutorado em Metodologia e Linhas de Investigação em Biblioteconomia e Documentação) - Universidade de Salamanca, Salamanca, 2014. Disponível em: https://comum.rcaap.pt/bitstream/10400.26/7171/1/TESIS\%20346.pdf. Acesso em: 10 set. 2017.

MOURA, M. A.; SILVA, A. P.; AMORIM, V. R. de. A concepção e o uso das linguagens de indexação face às contribuições da semiótica e da semiologia. 
Informação \& Sociedade, v. 12, n. 1, 2002. Disponível em: http://www.brapci.inf.br/index.php/article/view/0000001571/f872650acc92d0fdd d5252cce9cb7c9d/. Acesso em: 17 set. 2017.

NARUKAWA, C. M.; SALES, R. A relevância e influência de linguagens documentárias na política de tratamento da informação. In: GIL LEIVA, I.; FUJITA, M. S. L. (Ed.). Política de indexação. São Paulo: Cultura Acadêmica; Marília: Oficina Universitária, 2012.

NUNES, C. O. Algumas considerações acerca da ausência de políticas de indexação em bibliotecas brasileiras. Biblos: Revista de Bibliotecologia y Ciencias de la Información, Rio Grande, n. 16, p. 55-61, 2004. Disponível em: http://www.seer.furg.br/ojs/index.php/biblos/article/viewFile/411/96. Acesso em: 30 out. 2017.

RUBI, M. P. Proposta para implantação de política de indexação em bibliotecas. In: GIL LEIVA, I.; FUJITA, M. S. L. Política de indexação. São Paulo: Cultura Acadêmica; Marília: Oficina Universitária, 2012. p. 107-120.

SVENONIUS, E. The intellectual foundation of information organization. Cambridge: MIT Press, 2000.

VAN SLYPE, G. Lenguajes de indización: concepción, construcción y utilización en los sistemas documentales. Madrid: Fundación Germán Sánchez Rui Perez, 1991.

VIEIRA, A. P. F.; OLIVEIRA, L. P. de; CUNHA, T. M. Incursões sobre o tratamento temático da informação: estudo da política de indexação em bibliotecas universitárias goianas. Revista Informação em Pauta, Fortaleza, v. 2, n. 1, p. 28-49, jan./jun. 2017. Disponível em: http://www.repositorio.ufc.br/handle/riufc/24429. Acesso em: 21 out. 2017.

\title{
INDEXING LANGUAGES IN UNIVERSITY LIBRARIES: AN ANALYTICAL STUDY
}

\begin{abstract}
Introduction: The indexing language is a fundamental part of the indexing policy, considering its mediating role in the representation and retrieval of information. In order to know the reality in online catalogs of university libraries, an analytical study on language was carried out in the policy of indexing university libraries. Objective: The objective of the analytical study is to verify the use of indexing language by professionals, which language (s) they use, the existence of indexing policy manual and the use of construction and maintenance software available to the cataloger. Methodology: For this, a questionnaire was constructed and applied in a sample of university libraries in the southeast region of Brazil. Results: The questionnaire was answered by 60 libraries with the following profile: $60 \%$ have specialized collections from one to four subject areas, $73 \%$ of libraries have 1 to 3 professionals dedicated to indexing, $83 \%$ of libraries integrate a network or system, $50 \%$ participate in collective catalogs. With regard to use,
\end{abstract}

Inf. Inf., Londrina, v. 24, n. 1, p. 190 - 225, jan./abr. 2019. 
$49(89.1 \%)$ used some indexing language, 25 (51\%) used an indexing language, 20 with their own language without using specific software for construction and maintenance, and $24(49 \%)$ more than one language. Among libraries that use indexing language, 19 libraries adopt procedures when no terms are found in the language, 17 libraries update the language through semantic interoperability. The formalization of the indexing policy in a document is performed by $58.3 \%$ and only $22 \%$ do not describe the indexing language. Conclusions: The analytical study carried out with the application of the questionnaire reveals new scenarios in the use of indexing languages in libraries with advances, problems and gaps that are real challenges to be faced jointly by professionals and researchers.

Descriptors: Knowledge Organization. Indexing. Indexing languages. Indexing policy. University libraries.

\title{
LENGUAJES DE INDIZACIÓN EN BIBLIOTECAS UNIVERSITARIAS: ESTUDIO ANALÍTICO
}

\begin{abstract}
RESUMEN
Introducción: El lenguaje de indización es una parte fundamental de la política de indización, teniendo en cuenta su papel mediador en la representación y recuperación de la información. Para conocer la realidad en catálogos en línea de bibliotecas universitarias se realizó un estudio analítico sobre lenguaje en la política de indización de bibliotecas universitarias. Objetivo: El estudio analítico tiene el objetivo de verificar el uso del lenguaje de indización por los profesionales, qué lenguaje (n) utilizan, la existencia de manual de política de indización y el uso de software de construcción y mantenimiento disponible para el catalogador. Metodología: Para ello, fue construido y aplicado cuestionario en muestra de bibliotecas universitarias de la región sudeste de Brasil. Resultados: El cuestionario fue respondido por 60 bibliotecas con el siguiente perfil: $60 \%$ posee colecciones especializadas de una hasta cuatro áreas de tema, el $73 \%$ de las bibliotecas tiene de 1 a 3 profesionales dedicados a la indización, el $83 \%$ de las bibliotecas integran una red o sistema, $50 \%$ participan en catálogos colectivos. En cuanto al uso, se verificó que 49 (89,1\%) utiliza algúna lenguaje de indización, 25 (51\%) utilizan un lenguaje de indización, siendo 20 con lenguaje propio sin uso de software específico para construcción y mantenimiento, y 24 (49\%) más de una lenguaje. Entre las bibliotecas que utilizan lenguaje de indización, 19 bibliotecas adopta procedimientos cuando no se encuentran términos en el lenguaje, 17 bibliotecas actualizan el lenguaje a través de la interoperabilidad semántica. La formalización de la política de indización en documento es realizada por el $58,3 \%$ y sólo el $22 \%$ no describe el lenguaje de indización. Conclusiones: El estudio analítico realizado con aplicación del cuestionario revela nuevos escenarios en el uso de lenguajes de indización en bibliotecas con avances, problemas y lagunas que son verdaderos desafíos a ser enfrentados en conjunto por los profesionales e investigadores.
\end{abstract}

Descriptores: Organización del Conocimiento. Indización. Lenguajes de indización. Política de indización. Bibliotecas universitarias. 